\title{
Digital Addiction Level of Students and Teachers of Different Teaching Institutes of Jagdalpur
}

\author{
Pramod Singh, Raghvendra Patel, D. P. Singh
}

\begin{abstract}
This study was supported out to extract and examine the digital addiction level of the students and faculty members of Different Teaching Institutes of Jagdalpur, according to their devotions for using digital tools. 200 students from different stream and 100 faculty members are joined in this study. For data collection general survey model was adopted. Likert scales were used to make evaluation form which contains 21 questions related to involvement of respondents in digital tools. According to analysis of response given by respondent we find that $50 \%$ are teachers and students are digitally addicted. They are most time engaged with their digital devices.
\end{abstract}

Keyword: digital, addiction, Institutes, Different, Teaching Institutes of Jagdalpur,

\section{INTRODUCTION}

This is an era of digitalization of the world. Today digital tools are become necessary part of daily life of every one. This technological era has changed the perception of distance, time and space by speedily sharing of information from all over the world. Although, today most of works has been done by the digital tools very easily and quickly but overuse of the digital tools causes many physical as well as psychological problems. Continuous overuse of digital tools become addiction for users and this is called as digital addiction. We can define addiction as incitement upon habitude many number activity use which has devastating consequences on the physical and mental health of users. Today most of youth and children's of any country spending most of time in front of their digital devices and going to be addicted. Digital addiction includes playing game, social networking internet, Smartphone, communication etc. Now it is necessary to discover and examine the antagonistic effects of digital addiction on any individual. There are so many intimation of Digital Addiction Disorder may present in physical as well as emotional manifestations. The emotional intimation of digital addiction can be Depression, Agitation, Anxiety, Loneliness, Avoidance of Work etc. and the physical intimation of digital addiction may be Headaches, Carpal Tunnel Syndrome, Backache, Neck Pain and Dry Eyes. The goal of this study is to extract and examine the Digital addiction level among the students and teachers according to the frequency of uses and purposes of their digital devices.

Revised Manuscript Received on February 15, 2020.

* Correspondence Author

Dr. Pramod Singh*, Assistant Professor, School Of Studies Computer Application, Bastar University, Jagdalpur, India.

E-mail-pramodsinghbvv@gmail.com

Mr. Raghvendra Patel, Assistant Professor, School of Studies Computer Application, Bastar University, Jagdalpur, India. E-mailraghu1013@gmail.com

Mr. D. P. Singh, Assistant Professor, Indira Gandhi Krishi Vishwavidyalaya, Raipur, India. E-mail-dp_jagdalpur@rediffmail.com

(C) The Authors. Published by Blue Eyes Intelligence Engineering and Sciences Publication (BEIESP). This is an open access article under the CC BY-NC-ND license (http://creativecommons.org/licenses/by-nc-nd/4.0/)

\section{MATERIALS AND METHODS}

To carry out this study a survey method was used. To determine the DA level five point Likert scales used which contains five sub dimensions agree, Strongly agree, disagree, strongly disagree, and can't say. In present study main focus is given to the teachers and students using the digital tools in respect to social networking, game playing, internet, research, film-music, shopping, learning and communication. The data ware collected from online survey carried out among the teachers and students of different institutes of Jagdalpur and analyzed with SPSS.

\section{Ii.I Statistical Analysis}

Factor analysis is generally used to develop questionnaires in varies fields. We decided to plan a questionnaire to measure the addiction of digital tools among the students and teachers of different teaching institutes of Jagdalpur, Bastar. We granted questions based on interview with concerned respondents and came up with 21 possible questions to include. Each question is a statement which follows five-point likert scale having range from 'strongly disagree', 'disagree' strongly agree', 'agree' and 'neither agrees nor disagrees'. Questionnaires are made up of multiple items each of which elicits a response from the same person.

\section{Ii.Ii Sample Size}

Correlation coefficients mutate from one sample to another sample very much that's why the reliability of result of factor analysis is mostly dependent on sample size. Generally over 200 cases are probably adequate but communalities after extraction should probably be above 0.5 .

\section{Ii.Iii Data Screening}

Factor analysis finds a factor solution to multiple set of questions (variable). Howbeit, the solution is inconceivable to hold any true meaning if the variables that are analyzed are not appreciable. When conduction factor analysis it is necessary to understand association between the variables (questions).if the result of tested questions are produce the same basic element then we would imagine them to associate with each other.

\section{RESULT AND DISCUSSION}

Factor analysis is a method to test the relationships between a set of variables (questions) to identify the basic variables. A linear revolution is used for selection of a variable arrangement for the data set such that the highest difference of the data set arises on the first axis, 
The second highest difference on the second factor and so on. This technique is used on a data set with huge number of variables. Factor analysis using PC 1, PC 2, PC 3 and PC 4 was conducted for common source identification.

The problems related to digital addiction are correlated with four factor in which $50.32 \%$ of the total difference in the survey data was found.

Result indicates that, 4 factors contain $50 \%$ of the total variation of the 21 original variables (questions). PC 1/Factor 1 explains $26.64 \%$ of the variation with high loading factor (question2 (0.75), question 16(0.69), question 13(0.67), question10 (0.66), question1 (0.63), Question12 (0.62), Question5 (0.59), Question8 (0.58), Question11 (0.56), Question14 (0.55), Question15 (0.55), Question20 (0.52), Question18 (0.52), Question6 (0.50), PC 2/Factor 2 explains $11.24 \%$, Factor 3 explains $6.39 \%$ and factor 4 explains $6.03 \%$.the remaining other factors explains only $49.03 \%$. To analyze the result it is clear that the few starting factors clarify comparatively large quantities of difference (especially Factor 1) whereas subsequent factors explain only small amounts of variance. This association strongly advises that these variables have robust interrelationship.

In figure 1.1 we can see that the percentage of respondent in every loading factor (question). 35\% people are agreeing on spending more time with digital devices.

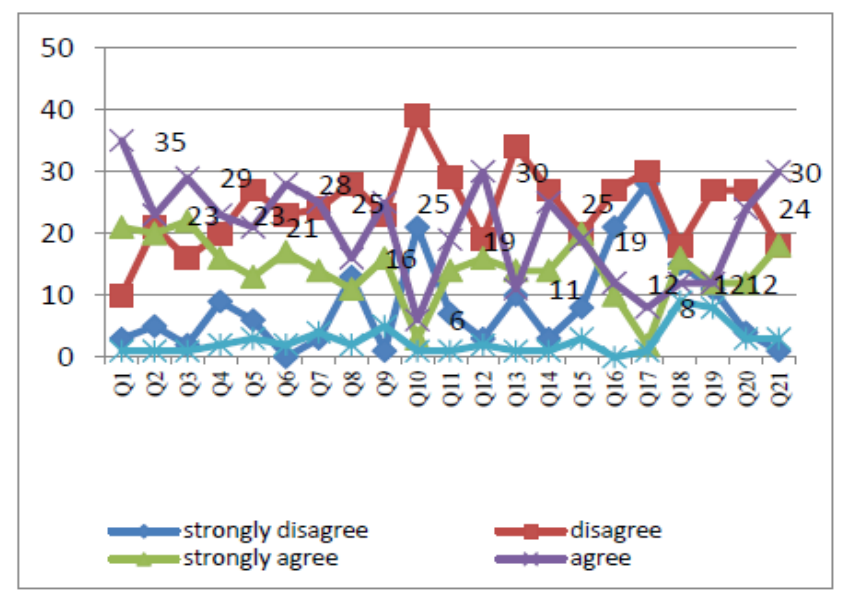

Figure1.performance graph

$23 \%$ people are finding her/her mindlessly passing time on regular basis by staring on smartphone and tablet or computer. 29\% are spending more time on smartphone for internet surfing. $23 \%$ are agree on sleep with smartphone on under pillow.21\% are agree on viewing and answering on social media at entirely hours of the day and night.28\% are agree on technology decreases his productivity at time.25 \%are agree on without digital device due to accidentally leave it in car or at home or there are no service or it is broken. $16 \%$ are agree on to his smartphone is always part of the table when he eating the food.25\% are agree on felling reluctant without smartphone or digital devices.6\% are agree on downloading and viewing adult materials.19\% are likes to tweeting and mailing as opposed to talk personally.30 \% are agree on checking smartphone mindlessly, though there is nothing important to see.11\% are agree on using smartphone while driving cars or similar activities. 25\% are agree on feeling lossless control or timelessness while using the internet.19\% are find him/herself restless or irritable when he trying to change or stop using smartphone or internet.12\% are jeopardized due to using smartphone or internet.18\% are committing illegal act related to use of internet.12\% are agree on his child are engaged most of time with smartphone.12\% are agree to spending time with virtual friends as opposed to real people.24\% are agree on spending most of time with social sites and 30\% people are using digital devices for business or other important productive works.

According to Factor analysis it is clear that the people who are agree on factor 1(PC1) which includes questions no. $1,2,5,6,8,10,11,12,14,15,16,18$ and 20 are digitally addicted. According to our sample size and analysis it is clear that $50 \%$ respondent are digitally addicted.

\section{SUGGESTED TREATMENT OF DIGITAL ADDICTION}

The first step is to identify the problem exist; if anyone don't find himself to any problem they do not need any treatment. If any problem exist then self-corrective behavior is prefer. Which includes to cutoff the time spending with digital devices, spend time with friends and family members, and go into social work. Spend time with other creative works real games.

\section{CONCLUSION}

Today we are breathing in a digital biosphere. Digital devices are become a necessary part of our life. Digital devices are making our daily work very easy and we are engaged most of time with these devices. This excessive engagement becomes us digitally addicted.in this paper we analyze that $50 \%$ respondents from different teaching institutions of jagdalpur are digitally addicted

\section{REFERENCE}

1. Alon, I. and R.K. Herath, Teaching International Business via Social Media Projects. Journal of Teaching in International Business, 2014 25(1): p. 44-59.

2. Barczyk, C.C. and D.G. Duncan, Social Networking Media: An Approach for the Teaching of International Business. Journal of Teaching in International Business, 2012. 23(2): p. 98-122.

3. Chou, W.P., et al., Association of stress coping strategies with Internet addiction in college students: The moderating effect of depression. Comprehensive Psychiatry, 2015. 62: p. 27-33.

4. Everson, M., Gundlach, E., Miller, J. , Social media and the introductory statistics course. . Computers in Human Behavior, 2013. 29(5): p. A69-A81.

5. Gafni, R. and M. Deri, Costs and benefits of Facebook for undergraduate students. Interdisciplinary Journal of Information, Knowledge, and Management, 2012. 7(1): p. 45-61.

6. Hong, F.-Y., et al., Analysis of the psychological traits, Facebook usage, and Facebook addiction model of Taiwanese university students. Telematics and Informatics, 2014. 31(4): p. 597-606.

7. Morahan-Martin, J., Internet abuse: Addiction? disorder? symptom? alternative explanations? Social Science Computer Review, 2005. 23(1): p. 39-48.

8. Oye, N.D., Adam, M. H., \& Nor Zairah, A. R. , Model of perceived influence of academic performance using social networking. International Journal of Computers and Technology,, 2012. 2(2): p. 24-29

9. Tang, J.K.T., et al., The Impacts on Learning via Social Media: A Study on Post-secondary Students in Hong Kong, in Technology in Education. Technology-Mediated Proactive Learning: Second International Conference, ICTE 2015, Hong Kong, China, July 2-4, 2015, Revised Selected Papers,

10. J. Lam, et al., Editors. 2015, Springer Berlin Heidelberg: Berlin, Heidelberg. p. 195-208. 
11. Vishal Kohli et. all,"A SURVEY- Academic Demolition via Internet Addiction", 2ndInternationalConference on Computing for Sustainable Global Development (INDIACom),IEEE,2015.

12. Whang, L.S.-M., S. Lee, and G. Chang, "Internet Over-Users' Psychological Profiles: A Behavior Sampling Analysis on Internet Addiction" Cyber Psychology \& Behavior, 2003. 6(2): p. 143-150.

\section{AUTHORS PROFILE}

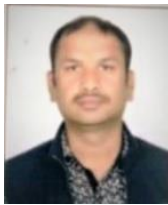

Dr. Pramod Singh, Assistant Professor, School Of Studies Computer Application, Bastar University, Jagdalpur(CG)

Mob-9691078337

E-mail-pramodsinghbvv@gmail.com

Qualification- MCA + Ph.D Area of research-

Database Security

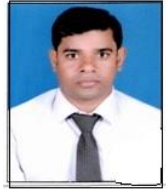

Mr. Raghvendra Patel, Assistant Professor, School Of Studies Computer Application, Bastar University, Jagdalpur (CG)

Mob-7583060214 E-mail-raghu1013@gmail.com

Qualification- B.TECH + M.TECH Area of research-

Cryptography

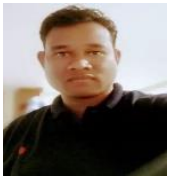

Mr. D.P. Singh, Assistant Professor, Indira Gandhi Krishi Vishwavidyalaya, Raipur

Mob-7987361188

$\underline{\text { E-mail- }}$

dp_jagdalpur@rediffmail.com

Qualification- MSc. (Ag) + NET (ICAR) Area of research- Statistical Analysis 